GEOLOGICA BALCANICA 50 (3), Sofia, December 2021, pp. 23-27.

\title{
Correlation between the liquid limit of clay derived by the Vasiliev and Casagrande test methods
}

\author{
Boriana Tchakalova, Boyko Berov \\ Geological Institute, Bulgarian Academy of Sciences, Acad. G. Bonchev Str., Bl. 24, 1113 Sofia, Bulgaria; \\ e-mails: boriana@geology.bas.bg; b_berov@geology.bas.bg
}

(Received: 25 October2021; accepted in revised form: 19 November 2021)

\begin{abstract}
The liquid limit is one of the most commonly used index properties of soils. The paper compares liquid limit values determined by the Vasiliev cone penetrometer method and by the Casagrande cup method, based on 45 natural clay samples collected from the Kozloduy Town area (North Bulgaria). An empirical correlation based on these liquid limit results has been derived.
\end{abstract}

Tchakalova, B., Berov, B. 2021. Correlation between the liquid limit of clay derived by the Vasiliev and Casagrande test methods. Geologica Balcanica 50 (3), 23-27.

Keywords: liquid limit, loess soil, Casagrande apparatus, Vasiliev apparatus.

\section{INTRODUCTION}

The most important characteristic of cohesive soils, with respect to their engineering behaviour, is consistency. The consistency of cohesive soils is identified by critical water contents at certain limits, the Atterberg limits: liquid limit $\left(w_{L}\right)$ and plastic limit $\left(w_{P}\right)$, which are basic in the classification of cohesive soils.

The $w_{L}$ parameter, also known as the upper plastic limit, was first defined by Swedish chemist and agricultural scientist Albert Atterberg (1911) and later refined and standardized by Arthur Casagrande (1958) for application in geotechnical research and practice. In addition, a number of geotechnical properties of soil have direct or indirect correlations with the $w_{L}$ value, e.g., compressibility, shear strength, swelling potential, permeability, liquefaction and cation exchange capacity.

Two basic methods for the evaluation of $w_{L}$ are in use, namely fall cone penetrometer test and Casagrande cup test. Both methods are adopted as a standard in many countries. The Casagrande test has been taken in geotechnical standards in the USA (ASTM, AASHTO), the United Kingdom (BSI), European Union (EN), Japan (JIS) and many other countries. The Vasiliev cone penetrometer test was previously chosen as a standard for the evaluation of $w_{L}$ in Bulgaria (BDS 648:1984), as well as in most Eastern European countries, including the former USSR (GOST 5184:85), Poland (PN-B04481:1988) and others.

BDS 648:1984 was in force until 2010; afterwards, geotechnical investigations and testing in Bulgaria have been performed according to the European norms (EN), where the Casagrande test is one of methods for $w_{L}$ determination (BDS EN ISO/TS 17892-12:2018). Both methods are based on measuring the shear strength $\left(s_{u}\right)$ of the soil. At the $w_{L}$ in the Casagrande test, $s_{u}$ is $1-3 \mathrm{kN} / \mathrm{m}^{2}$, while in the Vasiliev test it is $8.5 \mathrm{kN} / \mathrm{m}^{2}$ (Škopek and TerStepanian, 1975). As a result, the $w_{L}$ values obtained by each test differ significantly.

Since the ground basis in Bulgaria consists predominantly of clayey soils, plenty of geotechnical 
investigation tests performed before 2010 are available. There is a necessity for these archive results to be used in new projects and studies. Therefore, a correlation between the $w_{L}$ values determined by the Vasiliev test $\left(w_{L}^{V}\right)$ and the Casagrande test $\left(w_{L}^{C}\right)$ would have a useful application.

The objective of the present study is to compare the results for liquid limit values of clayey soils determined by the Vasiliev cone and Casagrande cup apparatuses, and consequently, an empirical correlation between $w_{L}^{V}$ and $w_{L}^{C}$ for such soils to be derived. For that purpose, the $w_{L}$ of 45 clayey soil samples was determined by the Vasiliev cone penetrometer method, in line with BDS 648:1984, as well as by the Casagrande method conforming to BDS EN ISO/ TS 17892-12:2018. Based on a regression analysis of the test results, an empirical correlation has been obtained.

\section{MATERIALS AND METHODS}

Forty-five samples of Quaternary and Pliocene clay soils from the Kozloduy Town area (North Bulgaria) were used in the present study. The soil samples were collected from borehole cores at different depths, mainly from $10 \mathrm{~m}$ to $50 \mathrm{~m}$ below ground level. Grain size distribution, particle density, plasticity limits, $w_{P}$ and $w_{L}$ were determined for each sample.

The liquid limit $w_{L}$ was defined according to BDS 648:1984 and BDS EN ISO/ TS 17892-12:2018. The $w_{L}$ tests were fulfilled at a room temperature of $20{ }^{\circ} \mathrm{C}$ by the same operator in order to reduce the possibility of human error. Measurements were run on duplicates to compare the results for each standard.

The $w_{L}^{V}$ values were determined with a Vasiliev cone penetrometer with a mass of $76 \pm 0.05 \mathrm{~g}$, height of $25 \mathrm{~mm}$, apex angle of $30^{\circ} \pm 0.1^{\circ}$ and fall time of $5 \pm 1 \mathrm{~s}$ over a molded sample of soil as suggested by BDS 648:1984. In line with standard procedure, at least four data points at different water contents were taken. The water content corresponding to a cone penetration of $10 \mathrm{~mm}$ defines $w_{L}^{V}$, which was calculated on the linear graph obtained by plotting water contents against their corresponding penetration values.

As recommended in 5.4 of BDS EN ISO/ TS 17892-12:2018, the Casagrande apparatus with a hard base percussion cup and 25 blows was used to obtain the $w_{L}^{C}$ values, and at least four data points at different water contents were taken. The water content corresponding to 25 blows was calculated on the linear graph derived by plotting water contents against corresponding number of blows. In order to classify the soil samples, $w_{P}$ was also determined according to BDS EN ISO/ TS 17892-12:2018.

The least square linear analysis was used to model the relationship between $w_{L}^{V}$ and $w_{L}^{C}$. This method calculates the best-fitting line for the observed data by minimizing the variance, i.e., the sum of squares of the errors. The analysis was performed and single-factor model of linear regression equation was obtained, expressed by the formula:

$$
\breve{y}=b_{0}+b_{1} x,
$$

where $\breve{y}$ denotes the predicted value of $y$ for a given $x$ and parameters of the model, $b_{0}$ is the intercept on the y-axis and $b_{1}$ is the slope of the straight line.

The $w_{L}^{V}$ was used as an independent variable $(x)$ to explain the dependent variable $w_{L}^{C}(y)$. In order to estimate the quality of the regression fit, the determination coefficient $\left(R^{2}\right)$, expressed by the following formula, was used:

$$
R^{2}=\frac{\sum_{i=1}^{n}\left(\check{y}_{i}-\bar{y}\right)^{2}}{\sum_{i=1}^{n}\left(y_{i}-\bar{y}\right)^{2}},
$$

where $n$ is the number of cases, $y_{i}$ is the observations of dependent variable, $\bar{y}$ is the mean of the observed data of dependent variable, and $\check{y}_{i}$ is the predicted value of dependent variable (Draper and Smith, 1998).

$R^{2}$ gives an idea of the percentage of change that takes place in the dependent variable, which can be explained by the change in the independent variable and ranges from 0 to 1 . Low values indicate that the outcome is relatively unrelated to the predictor, whereas values close to 1 indicate that the two variables are highly related.

\section{RESULTS AND DISCUSSION}

The test results carried out on the samples are presented in Table 1. Based on the particle size distribution, liquid limit and plasticity index, according to the ESCS, 15 samples were classified as medium plasticity clay (ClM) and 30 samples were classified as high plasticity clay $(\mathrm{ClH})$ (Fig. 1).

Comparison of the liquid limits of the clayey soils, determined by the Vasiliev cone penetrometer $w_{L}^{V}$ and Casagrande method $w_{L}^{C}$, is shown in Fig 2. It was observed that the $w_{L}$ values determined by the Vasiliev cone penetrometer were mostly lower (in the range of 30-50\%) than those obtained by the Casagrande apparatus (in the range of $39-70 \%$ ). 
Table 1

Index and classification of the tested clay samples

\begin{tabular}{|c|c|c|c|c|c|c|c|c|c|}
\hline \multirow{2}{*}{$\begin{array}{c}\text { Sample } \\
\text { No. }\end{array}$} & \multirow{2}{*}{$\begin{array}{c}\rho_{s} \\
\mathrm{~g} / \mathrm{cm}^{3}\end{array}$} & \multicolumn{3}{|c|}{ Grain size distribution [\%] } & \multirow{2}{*}{$\begin{array}{c}\text { Activity } \\
\text { index }\end{array}$} & \multicolumn{2}{|c|}{ Liquid limit [\%] } & \multirow{2}{*}{$w_{P}[\%]$} & \multirow{2}{*}{ ESCS classification } \\
\hline & & Sand & Silt & Clay & & $w_{L}^{V}$ & $w_{L}^{C}$ & & \\
\hline 1 & 2.74 & 11 & 87 & 2 & 11.3 & 30.4 & 39 & 16.5 & $\mathrm{ClM}$ \\
\hline 2 & 2.76 & 9 & 91 & 0 & - & 30.6 & 41.3 & 15.7 & $\mathrm{ClM}$ \\
\hline 3 & 2.75 & 7 & 81 & 12 & 2.1 & 28.0 & 41.6 & 16.0 & $\mathrm{ClM}$ \\
\hline 4 & 2.73 & 8 & 83 & 9 & 2.9 & 28.8 & 42.1 & 16.2 & $\mathrm{ClM}$ \\
\hline 5 & 2.73 & 13 & 85 & 2 & 12.8 & 32.3 & 42.3 & 16.8 & $\mathrm{ClM}$ \\
\hline 6 & 2.74 & 7 & 93 & 0 & - & 29.2 & 43.1 & 16.5 & $\mathrm{ClM}$ \\
\hline 7 & 2.72 & 14 & 55 & 31 & 1.0 & 34.1 & 46.0 & 15.8 & $\mathrm{ClM}$ \\
\hline 8 & 2.72 & 14 & 56 & 30 & 1.0 & 36.0 & 46.2 & 15.3 & $\mathrm{ClM}$ \\
\hline 9 & 2.77 & 10 & 78 & 12 & 2.7 & 33.1 & 46.6 & 14.8 & ClM \\
\hline 10 & 2.78 & 11 & 59 & 30 & 1.0 & 35.4 & 46.7 & 17.3 & ClM \\
\hline 11 & 2.77 & 14 & 53 & 33 & 1.0 & 33.5 & 48.0 & 16.1 & $\mathrm{ClM}$ \\
\hline 12 & 2.77 & 14 & 52 & 34 & 0.9 & 36.8 & 48.5 & 17.1 & $\mathrm{ClM}$ \\
\hline 13 & 2.74 & 19 & 81 & 0 & - & 34.3 & 48.9 & 14.8 & $\mathrm{ClM}$ \\
\hline 14 & 2.73 & 15 & 85 & 0 & - & 36.3 & 49.2 & 18.7 & $\mathrm{ClM}$ \\
\hline 15 & 2.73 & 14 & 86 & 0 & - & 34.4 & 49.6 & 14.2 & $\mathrm{ClM}$ \\
\hline 16 & 2.72 & 14 & 81 & 5 & 6.8 & 35.0 & 51.5 & 17.4 & $\mathrm{ClH}$ \\
\hline 17 & 2.77 & 5 & 92 & 3 & 10.8 & 36.6 & 51.7 & 19.2 & $\mathrm{ClH}$ \\
\hline 18 & 2.73 & 12 & 70 & 12 & 2.7 & 38.4 & 52.0 & 20.0 & $\mathrm{ClH}$ \\
\hline 19 & 2.78 & 6 & 69 & 25 & 1.3 & 40.0 & 52.1 & 20.2 & $\mathrm{ClH}$ \\
\hline 20 & 2.77 & 9 & 78 & 13 & 2.7 & 36.5 & 52.9 & 17.3 & $\mathrm{ClH}$ \\
\hline 21 & 2.75 & 10 & 71 & 19 & 1.9 & 39.6 & 53.0 & 17.5 & $\mathrm{ClH}$ \\
\hline 22 & 2.74 & 14 & 65 & 21 & 1.7 & 37.7 & 53.1 & 16.8 & $\mathrm{ClH}$ \\
\hline 23 & 2.74 & 6 & 91 & 3 & 11.0 & 39.2 & 53.6 & 20.7 & $\mathrm{ClH}$ \\
\hline 24 & 2.76 & 6 & 90 & 4 & 8.4 & 40.0 & 54.1 & 20.7 & $\mathrm{ClH}$ \\
\hline 25 & 2.78 & 9 & 76 & 15 & 2.5 & 36.0 & 54.6 & 17.8 & $\mathrm{ClH}$ \\
\hline 26 & 2.75 & 10 & 60 & 30 & 1.2 & 40.5 & 55.9 & 20.1 & $\mathrm{ClH}$ \\
\hline 27 & 2.71 & 15 & 64 & 17 & 2.2 & 39.1 & 57.0 & 20.0 & $\mathrm{ClH}$ \\
\hline 28 & 2.75 & 5 & 56 & 39 & 1.0 & 41.3 & 57.5 & 19.6 & $\mathrm{ClH}$ \\
\hline 29 & 2.78 & 13 & 66 & 20 & 2.1 & 41.2 & 59.6 & 16.7 & $\mathrm{ClH}$ \\
\hline 30 & 2.76 & 7 & 73 & 20 & 1.9 & 43.4 & 60.1 & 21.9 & $\mathrm{ClH}$ \\
\hline 31 & 2.77 & 19 & 73 & 5 & 8.7 & 41.2 & 61.4 & 17.7 & $\mathrm{ClH}$ \\
\hline 32 & 2.77 & 5 & 60 & 35 & 1.2 & 41.9 & 61.7 & 20.8 & $\mathrm{ClH}$ \\
\hline 33 & 2.76 & 4 & 79 & 17 & 2.4 & 44.3 & 62.5 & 21.6 & $\mathrm{ClH}$ \\
\hline 34 & 2.76 & 16 & 66 & 18 & 2.3 & 43.0 & 62.9 & 20.7 & $\mathrm{ClH}$ \\
\hline 35 & 2.75 & 3 & 83 & 14 & 3.0 & 41.8 & 63.0 & 20.7 & $\mathrm{ClH}$ \\
\hline 36 & 2.74 & 1 & 86 & 13 & 3.1 & 45.3 & 63.0 & 22.7 & $\mathrm{ClH}$ \\
\hline 37 & 2.75 & 10 & 87 & 3 & 14.0 & 45.3 & 63.9 & 21.8 & $\mathrm{ClH}$ \\
\hline 38 & 2.74 & 8 & 66 & 26 & 1.7 & 45.6 & 65.0 & 21.2 & $\mathrm{ClH}$ \\
\hline 39 & 2.75 & 8 & 50 & 42 & 1.1 & 44.8 & 66.0 & 21.1 & $\mathrm{ClH}$ \\
\hline 40 & 2.74 & 6 & 55 & 39 & 1.2 & 43.4 & 67.1 & 21.9 & $\mathrm{ClH}$ \\
\hline 41 & 2.76 & 6 & 59 & 35 & 1.4 & 43.2 & 67.4 & 17.8 & $\mathrm{ClH}$ \\
\hline 42 & 2.75 & 8 & 57 & 35 & 1.4 & 47.8 & 67.4 & 19.4 & $\mathrm{ClH}$ \\
\hline 43 & 2.77 & 10 & 65 & 25 & 2.0 & 47.9 & 68.4 & 18.8 & $\mathrm{ClH}$ \\
\hline 44 & 2.72 & 15 & 69 & 16 & 3.0 & 48.4 & 69.3 & 21.4 & $\mathrm{ClH}$ \\
\hline 45 & 2.78 & 5 & 55 & 40 & 1.2 & 49.3 & 69.7 & 21.7 & $\mathrm{ClH}$ \\
\hline
\end{tabular}




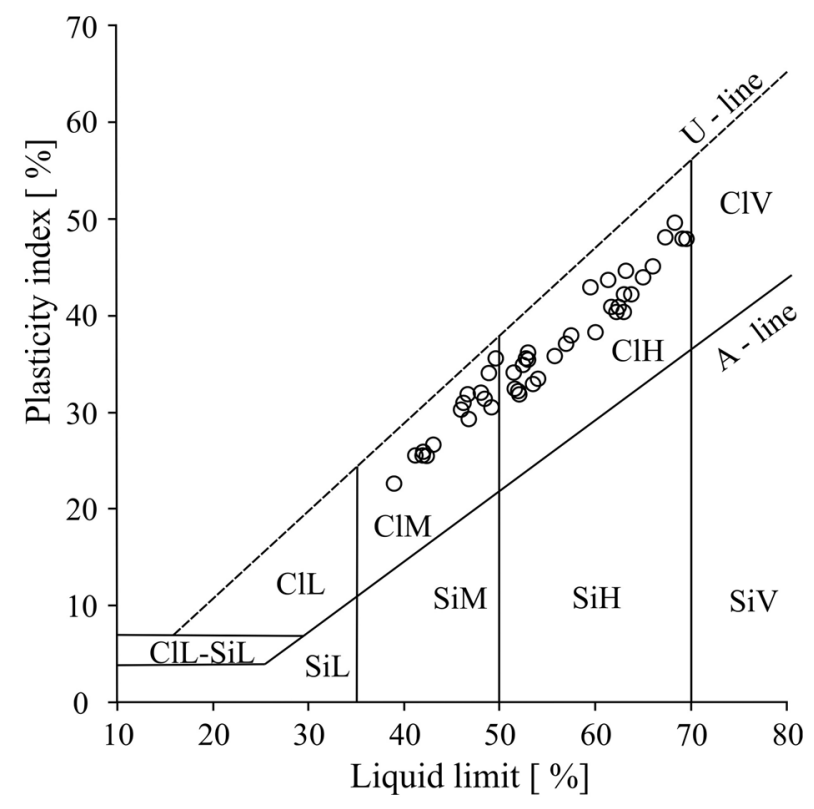

Fig. 1. Tested samples shown on Casagrande's plasticity chart (ESCS).

This is consistent with the results of other studies (e.g., Stefanoff, 1957; Škopek and Ter-Stepanian, 1975). The coefficient of determination is $R^{2}=0.92$ (Fig. 2), which means that there is a high correlation between liquid limits obtained by both methods. The following empirical correlation was derived from least square linear regression analysis:

$$
w_{L}^{c}=1.51 \times w_{L}^{v}-3.80,
$$

where $w_{L}^{C}$ is the Casagrande apparatus liquid limit, and $w_{L}^{V}$ is the Vasiliev cone penetrometer liquid limit. The high value of the coefficient of determination demonstrates the validity of the proposed relationship. The derived empirical equation is applicable for medium to high plasticity clayey soils with values of $w_{L}^{V}$ in the range of $30-50 \%$.

\section{CONCLUSION}

In order to compare liquid limit values of clay soil determined by the Vasiliev cone penetrometer (BDS 648:1984) and the Casagrande cup (BDS EN ISO/ TS 17892-12:2018), 45 clay samples were tested. The results indicated that:

- according to ESCS, 15 samples were classified as medium plasticity clay (ClM) and 30

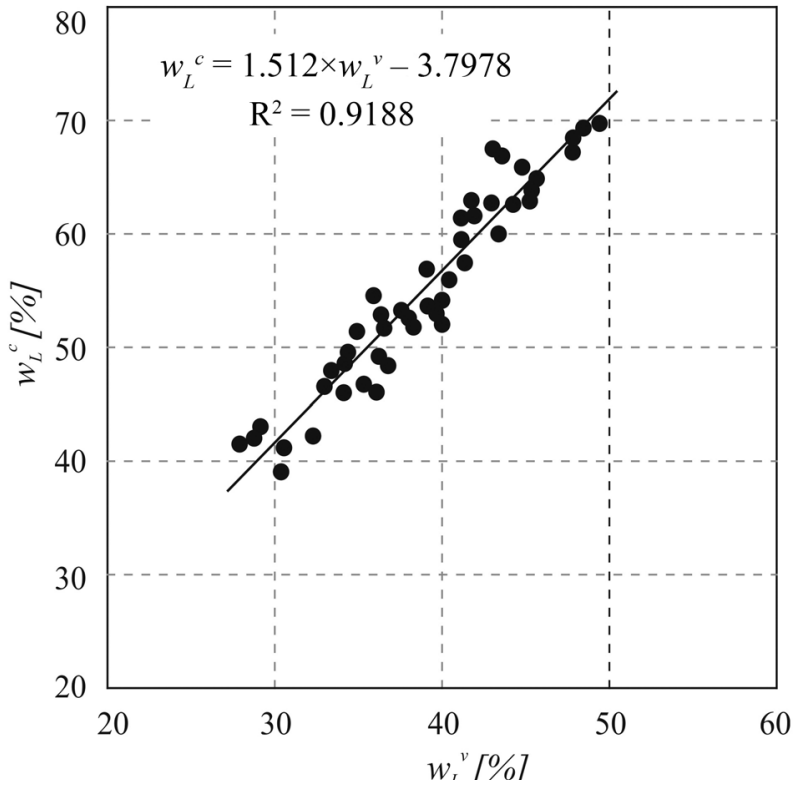

Fig. 2. Comparison of the liquid limit values determined by the standard Vasiliev cone penetrometer $\left(w_{L}^{V}\right)$ and the Casagrande apparatus $\left(w_{L}^{C}\right)$.

samples were classified into high plasticity clay $(\mathrm{ClH})$;

- the liquid limits determined by the Vasiliev cone penetrometer were rather lower than those obtained by the Casagrande cup apparatus;

- there is a strong correlation between liquid limits obtained by both methods $\left(R^{2}=0.92\right)$;

- an empirical correlation allowing conversion of the liquid limit obtained by the Vasiliev cone penetrometer to the liquid limit by the Casagrande cup apparatus has been derived. The model is not static, and new values could be incorporated, defining an updated equation.

\section{Acknowledgements}

The authors wish to thank two anonymous reviewers for their constructive reviews and suggestions, which improved the quality of the manuscript. This work has been carried out in the framework of the National Science Program "Environmental Protection and Reduction of Risks of Adverse Events and Natural Disasters", approved by the Resolution of the Council of Ministers № 577/17.08.2018 and supported by the Ministry of Education and Science (MES) of Bulgaria (Agreement No. DO1363/17.12.2020). 


\section{ABBREVIATIONS AND SYMBOLS}

$\begin{array}{ll}\text { BDS EN } & \text { Bulgarian State Standard European Norm } \\ \text { BDS } & \text { Bulgarian State Standard } \\ \text { ESCS } & \text { European Soil Classification System } \\ & \\ S_{u} & \text { Shear strength, } \mathrm{kN} / \mathrm{m}^{2} \\ w_{L} & \text { Liquid limit, } \% \\ w_{P} & \text { Plastic limit, } \% \\ I_{P} & \text { Plasticity index, } \% \\ \rho_{s} & \text { Particle density, g/cm }\end{array}$

\section{REFERENCES}

Atterberg, A. 1911. Die Plastizität der Tone. Internationale Mitteilungen der Bodenkunde 1, 4-37.

Casagrande, A. 1958. Notes on the design of the liquid limit device. Géotechnique 8 (2), 84-91, https://doi.org/10.1680/ geot.1958.8.2.84.

Draper N.R., Smith H. 1998. Applied regression analysis. Wiley \& Sons, New York, 736 pp., https://doi.org/10.1002/ 9781118625590.

Škopek, J., Ter-Stepanian, G. 1975. Comparison of liquid limit values determined according to Casagrande and Vasilev. Géotechnique 25 (1), 135-136, https://doi.org/10.1680/ geot.1975.25.1.135.

Stefanoff, G. 1957. Consistency of engineering soils. Bulletin of the Civil Engineering Institute 3, 159-197 (in Bulgarian).

Vasiliev, A. 1949. Fundamentals of modern methods and techniques for laboratory determination of the physical properties of soils. Mashstroyizdat, Moscow, 158 pp. (in Russian). 